\title{
JUNIOR DOCTORS' ATTITUDES TO OPIOIDS FOR REFRACTORY BREATHLESSNESS IN PATIENTS WITH ADVANCED CHRONIC OBSTRUCTIVE PULMONARY DISEASE
}

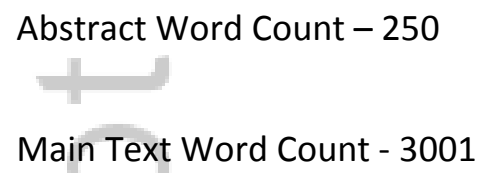

\section{Authors \& Affiliations}

Dr Natasha Smallwood. Respiratory Physician. Department of Respiratory and Sleep Medicine, The Royal Melbourne Hospital, Parkville, Victoria 3050, Australia.

Tel: 039342 7708. Fax: 039342 8493. Natasha.smallwood@mh.org.au

Dr Nicole Gaffney. Respiratory Physician. Frankston Hospital, 2 Hastings Road, Frankston, Victoria 3199. nicgaffney@gmail.com

Mrs Alexandra Gorelik. Senior Statistician. Melbourne EpiCentre, The Royal Melbourne Hospital, Parkville, Victoria 3050. alexandra.gorelik@mh.org.au

A/Prof Louis Irving. Respiratory Physician and Director Department of Respiratory and Sleep Medicine, The Royal Melbourne Hospital, Parkville, Victoria 3050, Australia. Louis.irving@mh.org.au

A/Prof Brian Le. Palliative Medicine Specialist and Director Department of Palliative Care, The Royal Melbourne Hospital, Parkville, Victoria 3050, Australia. Brian.le@mh.org.au A/Prof Jennifer Philip. Palliative Medicine Specialist and Deputy Director Centre for Palliative Care, St Vincent's Hospital, Victoria Parade, Fitzroy, Victoria 3065, Australia. Jennifer.philip@svhm.org.au

This is the author manuscript accepted for publication and has undergone full peer review but has not been through the copyediting, typesetting, pagination and proofreading process, which may lead to differences between this version and the Version of Record. Please cite this article as doi: $10.1111 / \mathrm{imj} .13521$

This article is protected by copyright. All rights reserved. 
Corresponding Author: Dr Natasha Smallwood

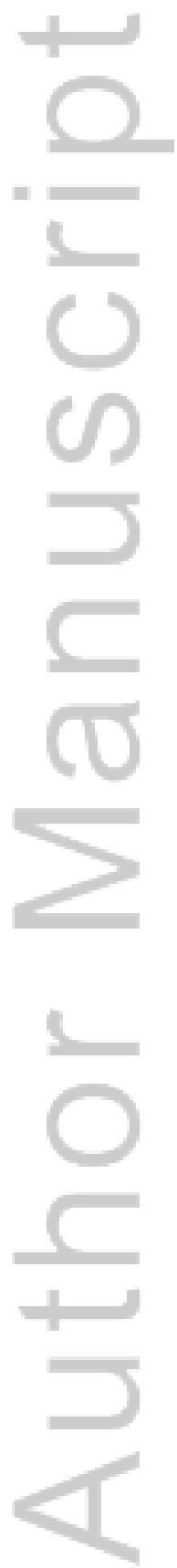

This article is protected by copyright. All rights reserved. 


\section{Introduction}

Chronic obstructive pulmonary disease (COPD) is a common, progressive condition, which is characterised by airflow limitation, persistent symptoms and respiratory failure (1). Many patients with severe COPD experience reduced quality of life due to refractory breathlessness (2). Refractory breathlessness is persistent breathlessness at rest or on minimal exertion despite optimal treatment of the underlying causes (3-5).

Managing refractory breathlessness can be challenging and usually requires both pharmacological and non-pharmacological treatment strategies. A series of studies suggest that low dose morphine may safely reduce refractory breathlessness in patients with advanced disease $(3,6-9)$. However, the addition of an opioid to treat refractory breathlessness, as an off-licence indication, requires cautious evaluation of benefits and risks, with dosing individualised for each patient and with close supervision and support in order to determine response and monitor for side effects (10).

Despite Australian and international COPD guidelines now recommending opioids to palliate breathlessness in advanced disease $(1,11-14)$, this distressing symptom remains undertreated, with lack of clinician knowledge or experience being a well-recognised barrier to opioid prescription (1517). Junior hospital doctors are at the 'front line' of tertiary medical care and therefore commonly manage, under consultant supervision, COPD patients with severe breathlessness. Consequently it is essential that junior doctors can identify patients who require specific attention to symptom palliation, and are aware of the various active management strategies for breathlessness.

This study aimed to understand Australian junior doctors' knowledge and attitudes regarding the management of refractory breathlessness and the role of palliative care in COPD. In this paper we report the study findings concerning attitudes to opioid prescription for refractory breathlessness.

This article is protected by copyright. All rights reserved. 


\section{Methods}

An anonymous and confidential survey was designed for junior doctors who had completed their first year of medical practice after qualification and who were undertaking basic training (training years 1-4) in internal medicine with the Royal Australasian College of Physicians in the state of Victoria, Australia.

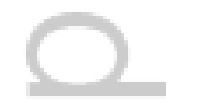

After a thorough literature search revealed no appropriate survey instrument for junior doctors, we developed a new survey (see supplementary data). Thirty-two questions were included, however not all questions were answered, as logic was embedded into the survey to determine the next question according to the previous response. The questionnaire included a case vignette, which described an optimally treated outpatient with severe COPD, and worsening, refractory breathlessness over many years. The patient in the case vignette had severe breathlessness with a Modified Medical Research Council breathlessness score of 4 out of 4 . Survey participants were told the case patient did not have anxiety and was not in the terminal phase (last few days) of his illness. Respondents were asked to consider how they would manage the case patient or COPD patients similar to the case. Survey questions focused on five themes: respondent demographics, management strategies for refractory breathlessness, the role of specialist palliative care, advance care planning and prognosis, and further education requirements.

The survey was piloted on 14 Basic Physician Trainees (BPTs) to ensure user acceptability, face validity, and comprehensiveness prior to full distribution. Over 4 months, each junior doctor in Victoria received two email invitations from their Director of Physician Training regarding the survey (which included the electronic survey link), approximately 2-6 weeks apart. Paper copies of the survey were also distributed at a single, face-to-face education event for junior doctors. Ethics approval was granted for this study by the Melbourne Health Research Office. 


\section{Statistical analysis}

Participant demographic data and responses are reported descriptively using frequencies and proportions. Proportions were calculated using the total number of respondents $(n=243$ for demographic data and $\mathrm{n}=223$ for all other questions), unless otherwise stated. Responder demographics (age and year in training program) were compared with demographic data for all BPTs in Victoria, which was kindly provided by The Royal Australasian College of Physicians. Content analysis of free text responses was undertaken with themes reported by frequency.

Either Pearson Chi-Squared or Fisher's exact test were used to identify associations between key exposure variables and outcomes, as appropriate. Exposure variables were defined as: age, gender, current year in training program, previous post in a non-metropolitan location, specialist palliative care teaching or training at medical school, having completed a post-graduate medical rotation with a specialist palliative care team, the duration of any previous post-graduate specialist palliative care medical rotation, the average number of patients seen per month with non-malignant conditions whilst completing a palliative care medical rotation, and the average number of COPD patients seen per month over the last 12 months.

Logistic regression models were used to further explore significant associations. Statistical analyses were performed using Stata12 (StataCorp, TX, USA), with a p-value of less than 0.05 indicating statistical significance.

\section{Results}

\section{Respondent demographics}

The survey was distributed to all BPTs in Victoria $(n=822)$, with $243(30 \%)$ responses received. Six BPTs had not cared for any COPD patients as a junior doctor, making them ineligible to continue the survey. Two hundred and twenty-three (92\%) trainees completed the full survey.

This article is protected by copyright. All rights reserved. 
Over three quarters of respondents $(188,77.4 \%)$ were aged between $20-30$ years (Table 1$)$. One hundred and eleven $(45.7 \%)$ respondents were male, with similar numbers in training years one to three (28.0-33.7\%). Most $(213,87.7 \%)$ BPTs had experience working in either a regional or remote Australian location. Respondents' demographics (gender and year of training) were representative of the total cohort of BPTs in Victoria in 2015.

One hundred and eighty-nine BPTs $(77.8 \%)$ had received some palliative care education at medical school receiving an average of 8 hours of lectures. One hundred and three $(42.4 \%)$ trainees reported undertaking a palliative care attachment at medical school, with an average duration of 2 weeks. Most $(150,61.7 \%)$ respondents had never worked as a junior doctor as part of a palliative care team. Two hundred and twelve (87.3\%) trainees reported caring for more than five COPD patients on average per month over the last 12 months.

\section{Pharmacological breathlessness management}

In response to the case vignette, most BPTs $(132,59.2 \%)$ believed a respiratory physician should direct the patient's long-term care, while $22(9.9 \%)$ trainees felt that this role should be filled by a palliative care specialist, and 36 (16.1\%) by a General Practitioner.

The majority of respondents $(198,88.8 \%)$ indicated they would consider adding a specific pharmacological treatment for the case patient's breathlessness, with 119 (53.4\%) trainees recommending immediate release morphine taken as required. Twenty four (10.8\%) suggested initiating daily, low-dose, extended release morphine (Table 2).

Willingness to add a specific treatment for the case patient's breathlessness was associated with years in the training program $(p=0.026)$, with more senior BPTs being more likely to recommend 
adding a specific breathlessness treatment $(p=0.013)$. Similarly willingness to add a specific breathlessness treatment was associated with seeing greater numbers of COPD patients over the past 12 months $(p=0.022)$.

Overall $193(86.5 \%)$ respondents believed opioids have a role in the treatment of refractory breathlessness in COPD patients, with female BPTs being more than twice as likely as males to believe opioids have a role (OR 2.3,95\% Cl 1.0-5.2, p=0.049). In addition, BPTs in year 2 and year 3 were more than twice $(\mathrm{OR} 2.7,95 \% \mathrm{Cl} 1.0-7.1, \mathrm{p}=0.048)$ and four times $(\mathrm{OR} 4.2,95 \% \mathrm{Cl} 1.3-13.6$, $\mathrm{p}=0.016$ ) as likely respectively, than year 1 BPTs to believe opioids have a role for treating breathlessness. Past experience working in non-metropolitan locations was also associated with being more likely to suggest that opioids have a role in treating refractory breathlessness $(p=0.047)$.

One quarter $(55,24.7 \%)$ of BPTs reported having themselves initiated an opioid for the treatment of refractory breathlessness, and 102 (45.7\%) had initiated an opioid under senior supervision for breathlessness management (Table 2). Previous experience prescribing opioids for refractory breathlessness was associated with having completed a postgraduate medical job with a specialist palliative care team $(p=0.005)$.

One quarter of all respondents $(58,26.0 \%)$ reported having no concerns prescribing an opioid medication for the case's refractory breathlessness (Table 3). The most common opioid concerns reported by BPTs included the risk of respiratory depression $(56,25.1 \%)$, gastrointestinal side effects $(34,15.3 \%)$, and sedation (16, 7.2\%). Only $3(1.3 \%)$ respondents believed that opioids should only be started by specialist palliative care and only $2(0.8 \%)$ were concerned opioids might hasten death.

Ninety $(40.4 \%)$ BPTs believed benzodiazepines have a role in the treatment of refractory breathlessness in COPD patients, who are not anxious and not in the terminal phase, while 17 (7.6\%)

This article is protected by copyright. All rights reserved. 
respondents recommended a low dose benzodiazepine as their additional first choice treatment for breathlessness. Holding the belief that benzodiazepines have a role in treating refractory breathlessness was not associated with any of the trainees' demographic characteristics.

\section{Further training and education}

Almost three quarters of respondents $(161,72.2 \%)$ wanted more training in the management of severe lung disease and $138(61.9 \%)$ wanted more training in the prescription of opioids for refractory breathlessness. Approximately half the respondents felt this training should occur during a medical rotation with a respiratory medicine team $(118,52.9 \%)$ or a palliative care team $(114$, $51.1 \%)$.

\section{Discussion}

This is the first study to specifically explore the attitudes of junior doctors to breathlessness management, and the only study to identify that these doctors report high awareness, confidence, willingness and experience prescribing opioids to COPD patients with refractory breathlessness.

\section{Opioid attitudes and prescription}

The majority of BPTs recognised the need for and were willing to prescribe additional treatments, such as morphine, to actively manage refractory breathlessness in patients with COPD. In our study the vast majority of respondents reported having experience in prescribing opioids for breathlessness in patients with COPD. Unsurprisingly experience of prescribing opioids for refractory breathlessness was associated with working as a postgraduate with a specialist palliative care team. However, only a third of trainees had completed such a post, thus this characteristic does not explain the overall high experience reported in prescribing opioids for refractory breathlessness. 
By contrast the preliminary results from an identical study using the same survey questionnaire completed by respiratory physicians and palliative medicine specialists in Australia, New Zealand and the U.K., demonstrated that only $63 \%$ of respiratory specialists would add an additional pharmacological treatment for refractory breathlessness in COPD, with only $51 \%$ recommending an opioid (18). Additionally only a third of the respiratory physicians reported prescribing opioids for refractory breathlessness regularly, with the remainder prescribing opioids only occasionally or never (18). Therefore the junior doctors surveyed in this study demonstrated significantly more willingness to both treat refractory breathlessness and use an opioid.

Internationally the findings regarding prescription of opioids for refractory breathlessness in COPD have been mixed. A survey of respiratory physicians and junior doctors in the Netherlands found that $81 \%$ of the 146 respondents had experience prescribing opioids to COPD patients with refractory breathlessness (19). Similarly a survey of 136 Portugese respiratory physicians, reported that $70 \%$ of respondents prescribed opioids to treat refractory breathlessness in COPD patients with a history of hospitalisation (20).

By contrast surveys of doctors from other countries have reported a reluctance to prescribe opioids to COPD patients with refractory breathlessness $(16,21)$. A recent survey of sixty-five UK doctors including 52 junior doctors, found that while $85 \%$ of respondents were aware of the use of opioids for refractory breathlessness, only $46 \%$ were willing and only $32 \%$ had experience in opioid prescription for breathlessness in COPD patients (16). Similarly a survey of 70 doctors in Canada found that while $98 \%$ had prescribed opioids for breathlessness in COPD, 39\% were uncomfortable prescribing opioids long term (21). However, both of these surveys had a small sample size and included individuals from only one or two sites, which may explain the differences compared with our study.

This article is protected by copyright. All rights reserved. 
In accordance with some international COPD guidelines $(12,22)$, BPTs in this study were much more likely to recommend initiating low dose, immediate release morphine taken as required (53\%), compared with sustained release morphine (11\%). Similarly the Canadian survey by Rocker et al found that the most commonly chosen starting dose for refractory breathlessness was immediate release morphine 1-2mg QID (21).

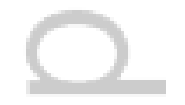

Surprisingly one quarter of respondents in our study reported having initiated themselves an opioid prescription for refractory breathlessness. However, in reality junior hospital doctors predominantly manage inpatients and work as part of a consultant-led team. Therefore it is unclear whether these reported opioid prescriptions were genuinely initiated and continued without senior supervision. Similarly the nature of working mainly with COPD inpatients, who often have exacerbations with worsening breathlessness and are under constant nursing observation, may explain the high experience prescribing opioids for breathlessness. Therefore perhaps the positive opioid attitudes and prescription practices reported by junior doctors in this study actually reflect changing attitudes and practices amongst senior physicians managing COPD patients with refractory breathlessness.

\section{Barriers to opioids}

Over one quarter of respondents reported having no concerns prescribing an opioid for refractory breathlessness in COPD and a further $18 \%$ did not answer this question. This unexpected finding is concerning for many reasons, not least because opioid use for refractory breathlessness is currently worldwide an off-licence prescription. Additionally whenever an opioid is being considered there must be a careful evaluation of the risks and benefits and these should be openly discussed with the patient and their carers.

In our study the most commonly reported opioid concern was the risk of respiratory depression (25\%). This is comparable to the Dutch survey in which $20 \%$ of doctors were worried about opioid 
induced respiratory depression (19). Meanwhile other small studies, including qualitative data, have reported concern regarding respiratory depression to be much higher, nearer $56-62 \%$ of doctors surveyed $(16,17,21)$. However, to date there have been no cases in the medical literature of respiratory depression from low dose opioids for the treatment of refractory breathlessness. Furthermore the most recent Cochrane systematic review of opioids for the palliation of breathlessness did not find a significant change in arterial blood gas oxygen or carbon dioxide levels (6).

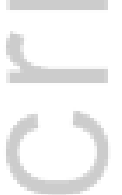

Junior doctors in our study expressed less concern regarding unpleasant and often predictable side effects such as constipation (11.7\%) or sedation (7.2\%), compared with doctors in the Netherlands (19). In the Dutch survey, $53 \%$ of doctors reported concern regarding each of these side effects. The greater concern expressed in their survey may have arisen as they included senior doctors. Additionally the junior doctors participating in our study may have had less opportunity to observe the long-term side effects, which outpatients commonly report and which occasionally lead to medication cessation.

Junior doctors reporting concern that the patient might be fearful of using opioids was low in this survey $(2.7 \%)$, compared to $30 \%$ of Canadian and $64 \%$ of Dutch doctors reporting patient resistance due to fear of death or addiction as a barrier to opioid prescription for refractory breathlessness (19, 21). The low experience of patient resistance reported in our survey might again have arisen due to junior doctors working predominantly with inpatients. In this setting multiple medication changes are made, frequently without detailed discussion with the patient or their family. By contrast outpatient initiation of opioids for COPD patients with refractory breathlessness requires skilled, patient and thoughtful communication, often over many consultations, to address patients' and families' concerns.

This article is protected by copyright. All rights reserved. 


\section{Other pharmacological treatments}

One quarter of respondents recommended benzodiazepines, long-term low dose prednisolone, nebulised bronchodilators or theophylline as first line treatments for chronic refractory breathlessness, even though there is no evidence to support these interventions and they are not part of COPD guidelines (1)'(23). As many of those treatments are associated with significant side effects and risks, there is a demonstrated need for further education of junior doctors regarding evidence-based, pharmacological management of refractory breathlessness.

\section{Further education \& training}

Surprisingly only $4 \%$ of Australian junior doctors, compared with $14 \%$ of Dutch respiratory specialists and residents, reported insufficient knowledge or experience as a barrier to prescribing opioids for breathlessness (19). Similarly in the UK, $55 \%$ of doctors surveyed were not confident prescribing opioids in this setting (16). However, although Australian junior doctors reported confidence, nearly three quarters expressed a desire for more training in the prescription of opioids for refractory breathlessness and in the management of severe lung disease. Additionally two thirds wanted more training in palliative care for patients with non-malignant disease. Their desire for further training is not surprising given the very limited undergraduate and postgraduate palliative care education and training reported by respondents. Similarly our findings reflects those of others, which have identified that many doctors want information and support (including a clear prescribing framework) to prescribe opioids for breathlessness (16), and many junior doctors desire more postgraduate palliative care education training generally (24).

\section{Limitations}

While quantitative surveys can be very useful and informative research tools, low response is a common and challenging issue, which is exacerbated by potential participants being overloaded with numerous online surveys requests. Our overall response rate was low (30\%), however, it was similar 
to other online surveys examining attitudes to opioids for refractory breathlessness $(19,20)$. It is unclear if the attitudes expressed by respondents in this study are generally those of junior doctors in Victoria or Australia or whether they differ from non-respondents. Nonetheless respondents' demographics were representative of the demographic characteristics of the total cohort of BPTs in Victoria at the time the survey was undertaken in 2015.

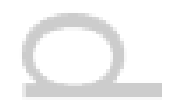

In our survey we asked about previous experience prescribing opioids, however, we did not ask respondents to quantify how often they had prescribed opioids for breathlessness. Therefore while we have identified a high awareness and reported experience prescribing opioids, it is impossible to know how frequently opioids really are prescribed for breathlessness in COPD. The survey of respiratory physicians and junior doctors in the Netherlands found $50 \%$ of the 146 respondents prescribed opioids to only $20 \%$ or less of their advanced COPD outpatients (19).

\section{Conclusions}

Australian junior doctors report high awareness, willingness and experience regarding prescribing opioids for refractory breathlessness in COPD. This represents a significant shift from the welldocumented physician reluctance to prescribe opioids generally. While this may lead to more proactive management of refractory breathlessness in the future, there must always be a judicious evaluation of benefit versus risk and a patient centred approach to opioid initiation. To address current gaps in knowledge significant further education and training, including establishing clear guidelines and a prescribing framework, are both required and desired to ensure that the demonstrated enthusiasm to alleviate distress is united with caution and individualised, patient focussed care.

This article is protected by copyright. All rights reserved. 


\section{References}

1. GOLD. Global initiative for chronic obstructive lung disease (GOLD). Global strategy for the diagnosis, management and prevention of COPD (2017 report). Available from:

http://www.goldcopd.org. Accessed January 2017. 2017.

2. Blinderman CD, Homel P, Billings JA, Tennstedt S, Portenoy RK. Symptom distress and quality of life in patients with advanced chronic obstructive pulmonary disease. J Pain Symptom Manage. 2009;38(1):115-23.

3. Abernethy AP, Currow DC, Frith P, Fazekas BS, McHugh A, Bui C. Randomised, double blind, placebo controlled crossover trial of sustained release morphine for the management of refractory dyspnoea. BMJ. 2003;327(7414):523-8.

4. Bausewein C, Booth S, Gysels M, Kuhnbach R, Haberland B, Higginson IJ. Individual breathlessness trajectories do not match summary trajectories in advanced cancer and chronic obstructive pulmonary disease: results from a longitudinal study. Palliat Med. 2010;24(8):777-86. 5. Burdon JG, Pain MC, Rubinfeld AR, Nana A. Chronic lung diseases and the perception of breathlessness: a clinical perspective. Eur Respir J. 1994;7(7):1342-9.

6. Barnes H, McDonald J, Smallwood N, Manser R. Opioids for the palliation of refractory breathlessness in adults with advanced disease and terminal illness. The Cochrane database of systematic reviews. 2016;3:CD011008.

7. Currow DC, McDonald C, Oaten S, Kenny B, Allcroft P, Frith P, et al. Once-daily opioids for chronic dyspnea: a dose increment and pharmacovigilance study. J Pain Symptom Manage. 2011;42(3):388-99.

8. Currow DC, Plummer J, Frith P, Abernethy AP. Can we predict which patients with refractory dyspnea will respond to opioids? J Palliat Med. 2007;10(5):1031-6.

9. Ekstrom MP, Bornefalk-Hermansson A, Abernethy AP, Currow DC. Safety of benzodiazepines and opioids in very severe respiratory disease: national prospective study. BMJ. 2014;348:g445.

10. Smallwood N, Le B, Currow D, Irving L, Philip J. Management of refractory breathlessness with morphine in patients with chronic obstructive pulmonary disease. Internal medicine journal. 2015;45(9):898-904.

11. Mahler DA, Selecky PA, Harrod CG, Benditt JO, Carrieri-KohIman V, Curtis JR, et al. American College of Chest Physicians consensus statement on the management of dyspnea in patients with advanced lung or heart disease. Chest. 2010;137(3):674-91.

12. Marciniuk DD, Goodridge D, Hernandez P, Rocker G, Balter M, Bailey P, et al. Managing dyspnea in patients with advanced chronic obstructive pulmonary disease: a Canadian Thoracic Society clinical practice guideline. Canadian respiratory journal : journal of the Canadian Thoracic Society. 2011;18(2):69-78.

13. Parshall MB, Schwartzstein RM, Adams L, Banzett RB, Manning HL, Bourbeau J, et al. An official American Thoracic Society statement: update on the mechanisms, assessment, and management of dyspnea. Am J Respir Crit Care Med. 2012;185(4):435-52.

14. Yang I, Dabscheck E, George J, Jenkins S, McDonald C, McDonald V, et al. The COPD-X Plan: Australian and New Zealand Guidelines for the management of Chronic Obstructive Pulmonary Disease 2016. Version 2.47, Oct 2016.: http://www.copdx.org.au; 2016.

15. Currow DC, Abernethy AP, Ko DN. The active identification and management of chronic refractory breathlessness is a human right. Thorax. 2014;69(4):393-4.

16. Hadjiphilippou S, Odogwu SE, Dand P. Doctors' attitudes towards prescribing opioids for refractory dyspnoea: a single-centred study. BMJ supportive \& palliative care. 2014.

17. Young J, Donahue M, Farquhar M, Simpson C, Rocker G. Using opioids to treat dyspnea in advanced COPD: attitudes and experiences of family physicians and respiratory therapists. Canadian family physician Medecin de famille canadien. 2012;58(7):e401-7.

18. Smallwood N, Currow D, Booth S, Spathis A, Irving L, Philip J. Physicians' attitudes to dyspnoea management in advanced Chronic Obstructive Pulmonary Disease (COPD). Eur Respir J. 2016;48(Suppl. 60):3748.

This article is protected by copyright. All rights reserved. 
19. Janssen DJ, de Hosson SM, bij de Vaate E, Mooren KJ, Baas AA. Attitudes toward opioids for refractory dyspnea in COPD among Dutch chest physicians. Chronic respiratory disease.

2015;12(2):85-92.

20. Gaspar C, Alfarroba S, Telo L, Gomes C, Barbara C. End-of-life care in COPD: A survey carried out with Portuguese Pulmonologists. Revista portuguesa de pneumologia. 2014;20(3):123-30.

21. Rocker GM, Young J, Horton R. Using opioids to treat dyspnea in advanced COPD: a survey of Canadian clinicians. Chest. 2008;134(4, Suppl 2 Meeting Abstracts):s29001.

22. Lanken PN, Terry PB, Delisser HM, Fahy BF, Hansen-Flaschen J, Heffner JE, et al. An official American Thoracic Society clinical policy statement: palliative care for patients with respiratory diseases and critical illnesses. Am J Respir Crit Care Med. 2008;177(8):912-27.

23. Simon ST, Higginson IJ, Booth S, Harding R, Bausewein C. Benzodiazepines for the relief of breathlessness in advanced malignant and non-malignant diseases in adults. The Cochrane database of systematic reviews. 2010(1):CD007354.

24. Weil J, Gold M, Mclver S, Rotstein L, Philip J. Australian resident doctors want more palliative medicine education: a survey of attitudes and perceived needs. Internal medicine journal.

2012;42(7):828-30.

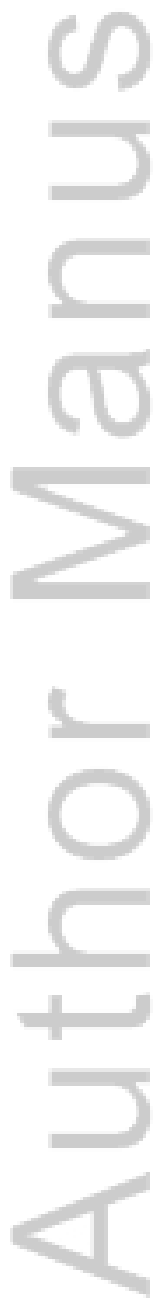

This article is protected by copyright. All rights reserved. 


\section{Acknowledgements}

The authors would like to thank the Victorian Directors of Physician Training (Andrew Brett, Wilma Beswick, Elke Hendrich, Nicholas Hewitt, Sam Hume, Edward Janus, Cameron Jeremiah, Douglas Johnson, Lisa Mitchell, Evan Newnham, Harvey Newnham, Darren Mansfield, Laila Rotstein, Judith Savige, Yana Sunderland and Amalie Wilke) for supporting and distributing the survey to their BPTs. We also thank Aaron Thompson at The Royal Australasian College of Physicians (Victorian Branch) for providing anonymous demographic data on all Victorian trainees. In addition we gratefully acknowledge Palliative Care Research Network for providing research funding for Dr Natasha Smallwood and the Australian Commonwealth Government for support through the Australian Government Research Training Program.

All authors contributed significantly to this manuscript and take responsibility for the analyses. Specifically, N Smallwood designed the study and survey questionnaire, organised survey distribution, analysed the data including some of the statistical analyses, and drafted the manuscript; N Gaffney designed the study and survey questionnaire, organised survey distribution and critically revised the manuscript for important intellectual content; A Gorelik performed the statistical analyses, interpreted the data and critically revised the manuscript for important intellectual content; L Irving designed the survey questionnaire and critically revised the manuscript for important intellectual content; B Le designed the survey questionnaire and critically revised the manuscript for important intellectual content; and J Philip designed the study and survey questionnaire, and critically revised the manuscript for important intellectual content.

This article is protected by copyright. All rights reserved. 


\section{Acronyms}

COPD - Chronic Obstructive Pulmonary Disease

BPT - Basic Physician Trainee

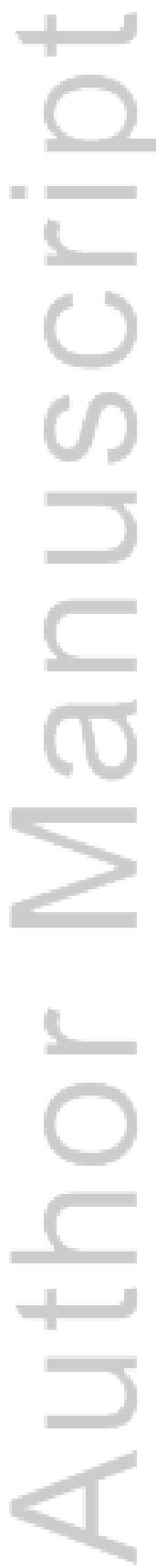

This article is protected by copyright. All rights reserved. 
Table 1. Participant characteristics and previous experience

\begin{tabular}{|l|r|}
\hline Characteristic & Frequency (n=243) \\
\hline Gender - Male & $111(45.7)$ \\
\hline Age & $31(12.8)$ \\
\hline $20-25$ & $157(64.6)$ \\
\hline $26-30$ & $42(17.3)$ \\
\hline $31-35$ & $10(4.1)$ \\
\hline $36-40$ & $3(1.2)$ \\
\hline$>41$ & \\
\hline Year in training & $73(30.0)$ \\
\hline BPT 1 & $82(33.7)$ \\
\hline BPT 2 & $68(28.0)$ \\
\hline BPT 3 & $14(5.8)$ \\
\hline BPT 4 & $6(2.5)$ \\
\hline BPT $\geq 4$ & \\
\hline Previously worked, in a non-metropolitan location & $185(76.1)$ \\
\hline Regional & $8(3.3)$ \\
\hline Remote & $20(8.2)$ \\
\hline Both regional \& remote & \\
\hline Previous palliative care education (n=243) & $86(35.4)$ \\
\hline Lectures or tutorials & $24(9.9)$ \\
\hline Clinical attachment & $79(32.5)$ \\
\hline Both lectures \& clinical attachment & \\
\hline Previous palliative care rotation as a junior doctor (n=238) & $67(27.6)$ \\
\hline Yes for under 3months & $21(8.6)$ \\
\hline Yes for over 3months & $20(8.2)$ \\
\hline Average number of COPD patients seen each month (n=232) & $75(30.9)$ \\
\hline$<5$ & $74(30.5)$ \\
\hline $6-10$ & $63(25.9)$ \\
\hline $10-20$ & \\
\hline$>20$ & \\
\hline \& & \\
\hline & \\
\hline & \\
\hline & \\
\hline & \\
\hline & \\
\hline & \\
\hline
\end{tabular}

Data are represented as frequencies with proportions in parentheses.

This article is protected by copyright. All rights reserved. 
Table 2. Pharmacological management of refractory breathlessness

\begin{tabular}{|l|r|}
\hline & Frequency \\
\hline Recommended pharmacological treatment for breathlessness (n=197) & \\
\hline Immediate release oral morphine (e.g. morphine 2.5-5mg 4-6 hourly prn) & $119(53.4)$ \\
\hline Low dose extended release morphine (e.g. 10-30mg morphine sulphate SR* daily) & $24(10.8)$ \\
\hline Benzodiazepine (e.g. lorazepam 0.5mg prn) & $17(7.6)$ \\
\hline Regular nebulised bronchodilators (e.g. salbutamol and ipratropium bromide) & $16(7.2)$ \\
\hline Long term low dose prednisolone (e.g. 5mg daily) & $14(6.3)$ \\
\hline $\begin{array}{l}\text { Do opioids have a role in treating refractory breathlessness in COPD patients } \\
\text { (n=221) }\end{array}$ & \\
\hline Yes & $193(86.5)$ \\
\hline No & $15(6.7)$ \\
\hline Don't know & $13(5.8)$ \\
\hline $\begin{array}{l}\text { Previous experience prescribing opioids for refractory breathlessness in COPD } \\
\text { patients (n=194) }\end{array}$ & \\
\hline Yes, initiated myself & $55(24.7)$ \\
\hline Yes, prescribed under the supervision of a consultant or advanced trainee & $102(45.7)$ \\
\hline No & $36(16.1)$ \\
\hline $\begin{array}{l}\text { Do benzodiazepines have a role in treating refractory breathlessness in COPD } \\
\text { patients (n=220) }\end{array}$ & \\
\hline Yes & $90(40.4)$ \\
\hline No & $72(32.3)$ \\
\hline Don't know & $58(26.0)$ \\
\hline
\end{tabular}

Data are represented as frequencies, with proportions calculated of all complete responses $(n=223)$ in parentheses.

* Sustained release

This article is protected by copyright. All rights reserved. 
Table 3. Trainees' concerns regarding prescribing opioids for breathlessness

\begin{tabular}{|l|r|}
\hline Opioid concerns & Frequency (n=183) \\
\hline “No concerns" specified & $58(26.0)$ \\
\hline Respiratory depression & $56(25.1)$ \\
\hline Gastrointestinal side effects - constipation, nausea or vomiting & $34(15.3)$ \\
\hline Sedation or drowsiness & $16(7.2)$ \\
\hline Addiction or dependence & $16(7.2)$ \\
\hline Accidental overdose & $14(6.3)$ \\
\hline Tolerance or increasing dosing requirements & $10(4.5)$ \\
\hline Misuse or abuse & $9(4.0)$ \\
\hline Insufficient knowledge or experience to prescribe opioids & $9(4.0)$ \\
\hline Patient needs opioid education & $9(4.0)$ \\
\hline Falls & $8(3.6)$ \\
\hline Opioid non-acceptance by the patient/family & $6(2.7)$ \\
\hline
\end{tabular}

Data are represented as frequencies, with proportions calculated of all complete responses $(n=223)$ in parentheses.

This article is protected by copyright. All rights reserved. 


\section{Abstract}

Refractory breathlessness is a common, distressing symptom in patients with advanced chronic obstructive pulmonary disease (COPD). The judicious, off-licence prescription of opioids, together with other management strategies, can improve breathlessness, however, internationally there is profound reluctance to prescribe opioids for breathlessness in COPD. Aims: To understand Australian junior doctors' knowledge and attitudes regarding the management of refractory breathlessness and the role of opioids in COPD.

Methods: All junior doctors undertaking basic training in internal medicine in Victoria were invited to complete an online survey. Knowledge, willingness, and experience prescribing opioids to COPD patients with refractory breathlessness, were examined.

Results: Of the 243 responses received, most trainees $(193,86.5 \%)$ believed opioids have a role in treating refractory breathlessness in stable COPD outpatients, with 143 (64.1\%) recommending morphine as first line treatment for refractory breathlessness. One quarter $(55,24.7 \%)$ reported having themselves initiated an opioid and $102(45.7 \%)$ had prescribed an opioid under senior supervision for management of breathlessness in COPD. Concern regarding adverse opioid effects was low, with 58 (26.0\%) having no concerns prescribing an opioid to COPD patients.

Conclusions: This is the first study of doctors to demonstrate high awareness, confidence, willingness and experience in prescribing opioids for the off-licence indication of refractory breathlessness in COPD. These findings differ significantly from attitudes reported overseas and are unexpected given the doctors surveyed were recently qualified. The low awareness of possible adverse events and limited insight regarding knowledge gaps is concerning and highlights the significant need for greater education in palliative care.

\section{Keywords}

COPD, dyspnoea, opioid, survey, attitude 


\section{University Library}

\section{- M M N E R VA A gateway to Melbourne's research publications}

Minerva Access is the Institutional Repository of The University of Melbourne

Author/s:

Smallwood, N;Gaffney, N;Gorelik, A;Irving, L;Le, B;Philip, J

Title:

Junior doctors' attitudes to opioids for refractory breathlessness in patients with advanced chronic obstructive pulmonary disease

Date:

2017-09-01

Citation:

Smallwood, N., Gaffney, N., Gorelik, A., Irving, L., Le, B. \& Philip, J. (2017). Junior doctors' attitudes to opioids for refractory breathlessness in patients with advanced chronic obstructive pulmonary disease. INTERNAL MEDICINE JOURNAL, 47 (9), pp.1050-1056. https://doi.org/10.1111/imj. 13521.

Persistent Link:

http://hdl.handle.net/11343/293397 